\title{
The benefits of central bank's political independence
}

\author{
Emmanuelle Gabillon ${ }^{\mathrm{a}, *}$, David Martimort ${ }^{\mathrm{b}}$ \\ ${ }^{a}$ University of Perpignan (GEREM), 52 Avenue Villeneuve, 66000 Perpignan, France \\ ${ }^{\mathrm{b}}$ Université de Toulouse 1 (GREMAQ, IDEI), France
}

Accepted 23 July 2002

\begin{abstract}
We consider a two-tier model of monetary policy where the central banker is both subject to the explicit influence of elected political principals through contracts and the implicit influence of interest groups willing to capture monetary policy. We analyze the impact of granting independence to the central banker on the scope for capture and the agency costs of delegating the monetary policy to a central banker. Political independence increases those agency costs but significantly stabilizes the politically induced fluctuations of inflation and improves ex ante social welfare.

(C) 2003 Elsevier B.V. All rights reserved.
\end{abstract}

JEL classification: D82; L51

Keywords: Monetary policy; Central banking; Independence; Partisan politics

\section{Introduction}

Our current understanding of how the design of credible monetary institutions ensures greater economic stability has been significantly improved by the contracting approach pushed forward by Walsh (1995), Persson and Tabellini (1993) and Svensson (1995). This principal-agent literature argues that the inflationary bias due to the time inconsistency of monetary policy ${ }^{1}$ can be avoided by delegating through contract the implementation of this policy to a central banker (thereafter CB) who is separated

\footnotetext{
* Corresponding author.

E-mail address: gabillon@univ-perp.fr (E. Gabillon).

${ }^{1}$ See Barro and Gordon (1983).
} 
from the main government body. ${ }^{2}$ This physical separation is often viewed as an ingredient of the CB's independence from the political sphere since it certainly insulates somewhat monetary policy from the day-to-day influence of political authorities and from fluctuations in the preferences of those political principals. However, the flip-side of this separation is that the $\mathrm{CB}$ may then be subject to various political pressures coming from organized interest groups willing to push their own views of what should be monetary policy. ${ }^{3}$

In this paper, we combine those two elements to obtain a more complete view of the political mechanisms which influence monetary policies. The CB is both subject to the explicit influence of elected political principals and to the implicit influence of interest groups which want to capture monetary policy. The choice of the CB legal status, i.e., whether he is independent or affiliated to the elected political principals, affects then the scope for capture of the monetary policy by private interests and different institutional choices lead to quite different policy outcomes. Under independence, the $\mathrm{CB}$ is less controlled by political principals and more responsive to interest groups. However, this status also isolates monetary policy from fluctuations in the identity of the elected political principals. As a result of this trade-off, the independence of the $\mathrm{CB}$ appears as an institutional best response to the threat of capture under political uncertainty.

Our view of central banking as balancing political versus private interests influences on monetary policy is inherited from Friedman (1962, 1972). According to him, central bank independence "embodies the very appealing idea that it is essential to prevent monetary policy from being a day-to-day plaything at the mercury of every whim of the current political authorities" but the flip-side of independence is that the CB becomes too much receptive to the "point of view of bankers", an organized interest group attempting to influence monetary policy. Consequently, Friedman rejected CB independence arguing that if elected politicians cannot be trusted for the conduct of monetary policy, "money is too important to be left to central bankers". The extreme solution suggested by Friedman was an inflexible monetary rule (a fixed growth rate of money) in order to "insulate monetary policy both from the arbitrary power of a small group of men not subject to control by the electorate and from the short-run pressures of partisan politics". This policy has of course a very high social cost both in terms of stabilization and in terms of non-responsiveness to changes in the preferences of society. In this paper, we take a less rigid view of what should be monetary policy

\footnotetext{
${ }^{2}$ A second standard solution to the credibility problem is to rely on reputation (see Rogoff (1989) for a survey). However, this non-institutional solution suffers from the well-known existence of multiple equilibria some of which still leave some room for discretionary policy. A third solution is to delegate the implementation of monetary policy to an inflation averse CB as in Rogoff (1985). As stressed by Walsh (1998, Chapter 8), this approach suffers from the fact that nothing prevents further delegation by the CB himself and, more importantly, from the fact that governments may find hard to distinguish among various central bankers with different preferences.

${ }^{3}$ As an example of capture of a CB, Cukierman (1998, Chapter 23) reports that, post to First World War, allies insisted on granting independence of the German $\mathrm{CB}$ from the German Chancelor to insulate this CB from the government's political pressures. This resulted in discount bills for private industrialists and bankers who, after the change, had better representation on the Board.
} 
and investigate how contracts and institutions for monetary policy can be designed to trade-off the desire to insulate monetary policies from political authorities and the need to make those institutions robust to capture by private interests.

To tackle these issues, we take a broad view of the control that a political principal exerts on the CB. These control rights involve not only the design of the CB's incentive scheme but also whether the $\mathrm{CB}$ can be removed or not after an election. When the $\mathrm{CB}$ is under political control, a newly elected political principal can choose a new $\mathrm{CB}$ affiliated to him. ${ }^{4}$ Instead, under political independence, the $\mathrm{CB}$ cannot be fired by the elected political principal. ${ }^{5}$ Contrary to the existing contracting literature, the CB's incentive contracts are not designed by social planners but by partisan political principals who want to please different constituencies and express thus different concerns for the trade-off between price control and surprise inflation depending on whether they represent a leftist or a rightist constituency. Because of informational asymmetry between the $\mathrm{CB}$ and the government, there is also scope for a collusion between private interest groups and the CB. ${ }^{6}$ However, the scope for capture depends on the exact control rights that principals retain on the $\mathrm{CB}$. In this framework, we ask whether granting political independence to the $\mathrm{CB}$ improves social welfare, whether more political independence makes monetary policy more sensitive to the influence of interest groups, and we finally investigate how those incentive contracts depend on the legal status of the $\mathrm{CB}$.

We show that the threat of capture on monetary policy increases the political fluctuations in monetary policy induced by the game of regime switching between rightist and leftist parties. Indeed, at the margin, left- and right-wing parties react differently to the threat of capture. The leftist party being more concerned by expansionary policies finds at the margin easier to fight capture by an anti-inflationist interest group. However, granting political independence to the $\mathrm{CB}$ somewhat insulates monetary policy from these political fluctuations: A stabilization effect. The cost of independence is nevertheless that the $\mathrm{CB}$ is more prone to capture by interest groups: $A$ delegation effect. The stabilization effect is always strong enough to dominate the delegation effect. Hence, ex ante social welfare is greater under political independence than under political control. When capture of the monetary policy is a crucial concern, it is socially optimal to reduce the politically induced fluctuations of inflation it induces. This is better achieved by granting political independence to the CB who better stabilizes those fluctuations around a middle-road policy. Political independence is thus an optimal institutional response to the threat of capture in a world of political uncertainty. ${ }^{7}$

\footnotetext{
${ }^{4}$ This extreme assumption is in fact a modeling short-cut to capture settings where the elected principal can change a significative number of Board members after the elections as in most countries.

${ }^{5}$ In practice, the status of the ECB sets the term of office for his President at 8 years reducing thereby the control of (often shorter lived) European governments on this CB.

${ }^{6}$ See Tirole (1986) and Laffont and Tirole (1993, Chapter 11) for similar collusion models in the regulation literature.

${ }^{7}$ Even though, we derive this result in a model where an anti-inflationist interest group exerts pressure on the government, it is independent on whether anti- or pro-inflationist pressures are exerted on the CB.
} 
The design of monetary institutions in a framework of regime switching between partisan political principals has already been addressed in models à la Rogoff (1985) where, instead of being corrected through an incentive scheme, the CB's preferences on the output-inflation trade-off can be chosen at the outset. The corresponding definition of independence is then related to the timing of the CB's appointment. A CB is independent when he is cooperatively appointed by the partisan parties before the elections. Along these lines, Waller (1989) and Alesina and Gatti (1995) show how politically induced fluctuations in output and growth can be stabilized under independence. In Alesina and Gatti (1995) for instance, political independence stabilizes inflation fluctuations because the private sector expectations are formed before any political uncertainty is resolved. By analyzing the difference in agency costs associated to the different legal status, we get a similar result without relying on the questionable assumption that private agents lock themselves into nominal contracts before the resolution of electoral uncertainty. ${ }^{8}$ Waller (1992) studies how the timing of appointments and elections affects the CB's degree of inflation aversion. ${ }^{9}$ Paralleling this insight in a contracting framework, we relate also the timing of nominations to the exact control rights exerted by the political principals and we investigate also how this timing affects agency costs, contract design and institutional choices. ${ }^{10}$ Finally, our analysis borrows the methodology of Faure-Grimaud and Martimort (2000) who provide a theory of political independence for regulatory agencies but we apply this framework to a more complex macroeconomic environment.

Section 2 presents the model. Section 3 analyzes the case of political independence. It stresses how the variance of inflation can be used as a tool to constrain collusive behavior between an anti-inflationist interest group and a CB.

Section 4 shows how the nature of this collusion changes under political independence and how the legal status of the $\mathrm{CB}$ affects the monetary policies chosen by partisan governments. We demonstrate there that political independence reduces the fluctuations in the variance of inflation. Section 5 provides some welfare analysis and discusses the optimal institutional choice. Section 6 introduces pro-inflationist groups and shows the robustness of our results. Section 7 concludes and discusses possible extensions of our framework. Proofs are relegated to an appendix.

\section{The model}

This model describes the relationship between an elected political principal, a CB and the private sector in a two-tier contracting model of monetary policy. The political principal can be thought of as the elected legislative or executive branch of the

\footnotetext{
${ }^{8}$ Garfinkel and Glazer (1994) argue for instance that "rational economic agents involved in contract negotiation are likely to time their activities to avoid uncertainty revolving around elections". They also show that economic agents expect different conditions under different political environments.

${ }^{9}$ See also O'Flaherty (1990) for a principal-agent model discussing the optimal term length of CBs.

${ }^{10}$ See also Waller and Walsh (1996) for some insights on the role of the CB's terms of office on the degree of surprise inflation.
} 
government. ${ }^{11}$ He maximizes the well-being of his constituency. Because he is better informed on economic conditions, the effective control of monetary target is left to a $\mathrm{CB}$ who has discretion in choosing the inflation target within those initially suggested by the political principal. The political principal has some control on his $\mathrm{CB}$ and can put some constraints on the agency decision-making process through the ex ante design of an incentive contract. ${ }^{12}$

\subsection{Preferences}

$C B$ : The $\mathrm{CB}$ receives a monetary transfer $s$ from whichever political principal gets elected. This transfer can be viewed as the budget of the $\mathrm{CB}$, his private benefits and "prestige" drawn from holding office or as a reduced form for his "career concerns". The CB's utility writes as $V=s$.

Political principals: Contrary to the whole contracting approach to central banking, the CB's incentive contract is not set by a benevolent legislature. Partisan political principals want indeed to please particular constituencies which give them political support. Following the "partisan politics" literature, political principals have different preferences regarding the trade-off between inflation and unemployment. Depending on whether they defend a "leftist" or a "rightist" constituency, they are more or less inclined to prefer suprise inflation to price stabilization. A political principal maximizes an objective function à la Barro and Gordon (1983):

$$
S W_{\alpha_{i}}=-\frac{\pi^{2}}{2}+\alpha_{i} \theta\left(\pi-\pi^{\mathrm{e}}\right)-s,
$$

where $\pi$ is the inflation level, $\pi^{\mathrm{e}}$ its expectations and $\alpha_{i}>0$ (with $i \in\{L, R\}$ ) is the weight that the political principal puts on creating surprise inflation. ${ }^{13,14} \theta$ is a macroeconomic shock affecting both political principals' concerns for output expansion. ${ }^{15}$

\footnotetext{
${ }^{11}$ Havrilesky (1993) and Froyen et al. (1993) have shown that the executive branches has a stronger influence than the legislative one on monetary policy conducted in the U.S.

12 This control can be explicit as in New Zealand nowadays but could also be more implicit. Beck (1987), for instance, argues that presidential preferences for monetary policy are somewhat transmitted to the Fed even if the exact mechanism requires further study. See also Wooley (1984) for a similar view.

${ }^{13}$ A quite similar objective function would also be obtained in a model where political principals have an objective function $S W_{\alpha_{i}}=-\pi^{2} / 2-\left(\alpha_{i} / 2\right)\left(y-y^{*}\right)^{2}$ and output is given by the Philips curve $y=\pi-\pi^{\mathrm{e}}+\theta$ as it can be easily checked by simple computations.

${ }^{14}$ Our results are robust to the exact specification of the marginal cost of the CB's wages in the principal's objective function. This means that they hold also if this objective function is written as $S W_{\alpha_{i}}=-\pi^{2} / 2+$ $\alpha_{i} \theta\left(\pi-\pi^{\mathrm{e}}\right)-\lambda_{s}$, for any $\lambda>0$. Introducing this extra parameter would only help to parameterize the size of the agency problem between the political principal and the $\mathrm{CB}$ without consequences on the main insights of the analysis. This also shows that even an infinitesimal value of $\lambda$ is enough to make the agency problem relevant for the optimal choice of institutions.

${ }^{15}$ Cukierman and Meltzer (1986) use the alternative formulation: $S W_{\alpha_{i}}=-\pi^{2} / 2+\left(\alpha_{i}+\theta\right)\left(\pi-\pi^{\mathrm{e}}\right)-s$ where the shock affecting the political principals' willingness to expand output enters additively. With such a formulation, there would be no difference between the monetary policies of a rightist and a leftist government under full commitment. Our multiplicative specification introduces such a difference. This difference turns out to be the crucial factor for the politically induced fluctuations of monetary policy.
} 
Finally, the CB's utility has no weight in the political principal's objective function since the latter is only concerned with the well-being of groups with significant electoral power. ${ }^{16}$

The random variable $\alpha_{i}$ may be either high $\left(\alpha=\alpha_{L}\right.$ with probability $\left.1-p\right)$ or low $\left(\alpha=\alpha_{R}\right.$ with probability $p$ ) depending on whether the elected government defends the leftist or the rightist constituency. A rightist government is less willing to create suprise inflation than a leftist one. We denote by $\Delta \alpha=\alpha_{L}-\alpha_{R}>0$ the degree of polarization of this society, i.e., the difference between the concerns for surprise inflation between a leftist party and a rightist one. As in most models of partisan politics, the probabilities that each of these two political principals gets elected are exogenous.

For further references, we define also a measure of aggregate social welfare as

$$
S W=-\frac{\pi^{2}}{2}+\hat{\alpha} \theta\left(\pi-\pi^{\mathrm{e}}\right)-s,
$$

where $\hat{\alpha}=p \alpha_{R}+(1-p) \alpha_{L}$. This expression is simply an average of both principals' objective functions weighted by the probability that each of them gets elected.

Interest groups: We first focus on the case of political pressures for anti-inflationist policies. ${ }^{17}$ A typical example of an anti-inflationist group is given by the financial sector. Indeed, as other authors have noticed, financial institutions earn their living by borrowing short and lending long. Similarly, securities dealers hold highly levered balance sheets. These groups are thus hurt by surprise inflation. ${ }^{18}$ Posen (1995) has also pushed the view that the financial sector provides the political support for the independence of the CB. As we will see below, this statement is consistent with the fact that the financial sector may benefit from the independence of the CB to increase the scope for capture. On related lines, Blinder (1999) underlines the strong influence of financial markets on monetary policy and the risk of such an influence when he claims "My point is simply that delivering the policy that [financial] markets expect-or indeed demand-may lead to very poor policy".

As a matter of fact, collusion between the $\mathrm{CB}$ and the banking system is more likely in countries where the $\mathrm{CB}$ supervises the banking system because supervision creates a particular link between the $\mathrm{CB}$ and the banking sector. The $\mathrm{CB}$ might consider that its prime objective is to protect the anti-inflationist objectives of banks and not to realize the optimal monetary policy. This is certainly why some countries, like United Kingdom, have recently removed supervision from the scope of their CB's activities.

\footnotetext{
${ }^{16}$ Alternatively, suppose that political principals' objective functions also involve the utility $V$ of the bureaucrat but that there is a positive cost of public funds $\lambda$. Then this objective function writes as $S W_{\alpha_{i}}=$ $-\pi^{2} / 2+\alpha_{i} \theta\left(\pi-\pi^{\mathrm{e}}\right)+V-(1+\lambda) s$ and, again, an infinitesimal value of $\lambda$ is enough to make the agency problem relevant for the optimal choice of institutions.

${ }^{17} \mathrm{We}$ discuss also in Section 6 how pro-inflationist interest groups could enter the picture.

${ }^{18}$ Kane (1980) argues that builders and construction unions form also anti-inflationist interest groups for similar reasons.
} 
The anti-inflationist interest group gets a utility from unexpected inflation which is equal to

$$
I G=-\beta \theta\left(\pi-\pi_{\mathrm{e}}\right)
$$

where $\beta$ is a positive parameter.

\subsection{Information}

The shock $\theta$ is drawn from a common knowledge distribution on $\Theta=\{\underline{\theta}, \bar{\theta}\}$ with respective probabilities $v$ and $1-v$. It is convenient for what follows to use the normalization $\bar{\theta}=1$ and we denote $\Delta \theta=1-\theta>0$. Anti-inflationist incentives are the thus greatest when $\underline{\theta}$ realizes.

The $\mathrm{CB}$ and the interest group have complete information on the shock $\theta$. Typically, the $\mathrm{CB}$ and the anti-inflationist financial sector have an earlier access to data relevant for determining money demand than the public. ${ }^{19}$ Instead, at the time of designing the CB's incentives, political principals and the (non-financial) private sector remain uninformed on the exact value of this shock. ${ }^{20}$

Political principals have to rely on a revelation mechanism to obtain this information from the CB.

This information structure has already been stressed by some authors. In an empirical analysis, Peek et al. (1999) have discussed the complementarity between bank supervisory responsibilities and monetary policy. They showed that confidential bank supervisory information could help the Board staff to obtain more accurately forecast on important macroeconomic variables and is used by FOMC members to guide monetary policy. Indeed, problems in the banking sector may serve as an early indicator of deteriorating macroeconomics conditions. Moreover, this information could provide advance notice of changes in bank lending behavior which would affect the credit channel of monetary policy.

Lastly, we assume that $\theta$ is a piece of information which cannot be fully manipulated. The $\mathrm{CB}$ can hide verifiable evidences on the fact that the economy is doing badly $(\bar{\theta})$ and announces instead that $\hat{\theta}=\underline{\theta}$. The mere possibility that the $\mathrm{CB}$ can hide such pieces of information will be key to understand the scope for collusion with an anti-inflationist interest group. On the contrary, the $\mathrm{CB}$ can make credible reports that the economy goes well by showing hard econometric evidences.

\footnotetext{
${ }^{19}$ Instead of assuming that the interest group and the CB shares the knowledge on $\theta$, one could assume that only the $\mathrm{CB}$ knows the true state of nature and can credibly release this information to the anti-inflationist interest group to initiate some collusion. As we will see below, collusion increases the supervisor's wage. Hence, the CB credibly sharing information may be rationalized as an equilibrium move in a model where the decision to share or not information is endogenized.

${ }^{20}$ Eventually all agents may get the same information set. However, what matters to design the CB's incentive contract is the information which can be made verifiable and thus contracted upon at the time of contracting.
} 


\subsection{Incentive contracts}

The grand-contract between the elected political principal and the CB consists of wages $s$ and inflation targets $\pi$. In our framework, the Revelation Principle applies and there is no loss of generality in restricting the elected principals to offer direct revelation mechanisms $\left\{\left(\underline{s}_{i}, \underline{\pi}_{i}\right) ;\left(\bar{s}_{i}, \bar{\pi}_{i}\right)\right\}$ where $i \in\{R, L\}$. The CB chooses within this menu according to his report on the state of the economy. ${ }^{21}\left(\underline{s}_{i}, \underline{\pi}_{i}\right)$ (resp. $\left.\left(\bar{s}_{i}, \bar{\pi}_{i}\right)\right)$ represents, respectively, the wage and the inflation target when the economy goes well $\underline{\theta}$ (resp. goes badly, $\bar{\theta}){ }^{22}$

\subsection{Capture}

We model the congruence of interests between anti-inflationist interest groups and the CB as a collusion, or side-contract, along the lines of Tirole $(1986,1992)$ and Laffont and Tirole (1993, Chapter 11). By bribing the CB, the interest group influences the latter's choice of inflation target within the menu proposed by the elected political principal.

Scope for capture: When a bad state of the economy realizes, the anti-inflationist interest groups would like that the $\mathrm{CB}$ reports $\underline{\theta}$ to keep inflation low. By having the $\mathrm{CB}$ misreport to the political principal, the interest group benefits from a stake which is equal to $\beta \bar{\theta}\left(\left(\bar{\pi}_{i}-\pi_{i}^{\mathrm{e}}\right)-\left(\underline{\pi}_{i}-\pi_{i}^{\mathrm{e}}\right)\right)=\beta \Delta \pi_{i}$. The interest group is not willing to bribe the $\mathrm{CB}$ for misreporting when $\underline{\theta}$ realizes since doing so would increase inflation. ${ }^{23}$

Transaction costs of side-contracting: The interest group influences the CB through monetary bribes. Making this assumption is an helpful modeling short-cut since these bribes may actually take the form of various in-kind or implicit favors. ${ }^{24}$ However, because of the illegal nature of capture, the side-contract between this group and the CB suffers from some transaction costs. ${ }^{25}$ Transferring $\tau$ units of wealth to the CB increases his private benefits from holding office only by $K(\tau)$ where $\tau-K(\tau)$ represents the transaction costs of side-contracting. To characterize explicitly the institutional response to the threat of capture, we stipulate a particular functional form for $K(\tau)$, namely:

$$
K(\tau)=k \tau-\frac{r}{2} \tau^{2}
$$

\footnotetext{
${ }^{21}$ Of course, in the real world, the $\mathrm{CB}$ sets the short-term nominal interest rate instead of the inflation rate. We take this short-cut to focus on the political economy of the model in the simplest way.

${ }^{22}$ As in any principal-agent model, ex post once the $\mathrm{CB}$ has chosen the monetary policy within the menu that will be proposed by the principal, the principal gets information and would like to renegotiate the menu. However, this renegotiation possibility would be anticipated by the CB and the cost of it would be imperfect revelation in the first place. Assuming full commitment by the political principals helps us to define an upper bound on what can be achieved under the threat of capture.

23 This absence of any scope for collusion justifies also our information structure assuming that $\underline{\theta}$ is the only state of nature which can indeed be manipulated.

${ }^{24}$ Dixit (1998) also models the implicit influence on a European CB exerted by non-cooperating national governments in a common agency framework with explicit side-transfers.

${ }^{25}$ See Tirole (1992) for an exhaustive discussion of the origins of these transaction costs.
} 
where $0<k \leqslant 1$ and $r>0$. We consider constellations of parameters such that potential bribes will belong to the interval $\left[0, \frac{k}{r}\right]$ where $K(\cdot)$ is increasing. Note also that $K(\cdot)$ is strictly concave. These two assumptions capture the fact that transferring more wealth to the $\mathrm{CB}$ makes easier for the interest group to affect his decision-making but that the marginal efficiency of doing so decreases. ${ }^{26}$

Lastly, the $\mathrm{CB}$ has all the bargaining power at the side-contracting stage and appropriates most of the gains of his collusion with the interest group. The bribe given to the $\mathrm{CB}$ when he misreports the state of nature is thus worth the whole stake of capture, $\beta \Delta \pi_{i}$.

\subsection{The legal status of the central bank}

The CB has political independence (hereafter superscript PI) when he cannot be removed from office by newly elected political principals. Political independence does not mean that the elected political principal loses all control on the $\mathrm{CB}$ since the $\mathrm{CB}$ still receives a contract from this elected principal. ${ }^{27}$ Under independence, the elected political principal has lost only his control of the appointment procedure for members of the board of the central bank. Under political control (hereafter superscript PC), a new $\mathrm{CB}$ is appointed each time a new political principal gets elected. The principal has control rights on who should be the head of the central bank.

\subsection{Timings of the game}

The timing of the game depends on the legal status of the central bank only through the new collusion possibilities that independence opens.

We first envision the case where a new $\mathrm{CB}$ is appointed each time a new political principal gets elected.

$T=0$ : The electoral outcome realizes and the preferences of the elected political principal $\alpha_{i}$ are known by all players including the private sector of the economy.

$T=1$ : The $\mathrm{CB}$ receives a grand-contract from the political principal who has just been elected. This contract stipulates wages and inflation targets. The private sector forms its expectations on inflation and negotiates wage contracts.

$T=2$ : Ex post collusion stage. If he has accepted the grand-contract, the CB offers a side-contract to the interest group. This side-contract is accepted or refused.

$T=3: \theta$ is learned by the $\mathrm{CB}$ and the interest group.

$T=4$ : The $\mathrm{CB}$ makes an announcement $\hat{\theta}$ on the state of the economy and the corresponding inflation target and wage are implemented. Side-transfers, if any, are exchanged.

\footnotetext{
${ }^{26}$ Note that the technology of side-contracting is also independent of the legal status of the CB. It is a priori as easy to capture an independent $\mathrm{CB}$ and a non-independent one.

${ }^{27}$ In most developed countries, the $\mathrm{CB}$ is indeed always (at least informally) vertically subordinated to either the executive or the legislative branch of the government. Our definition of political independence fits thus with that given in Grilli et al. (1991).
} 
An important assumption should be stressed at this point. The fact that the CB is affiliated to a particular political principal and is only removed once a new political principal gets elected implies that the collusive side-contract can only be signed ex post, i.e., once the elected political principal has already appointed his CB.

Under political independence, political parties propose monetary policies to the $\mathrm{CB}$ before political uncertainty resolves. ${ }^{28}$ One can view these proposals as the campaign platforms of the two candidates. ${ }^{29}$ Collusion can now takes place also ex ante.

$T=0$ : Both political parties propose non-cooperatively their electoral platforms. These platforms consist of incentive contracts to the CB. These grand-contracts stipulate budgets and inflation targets conditionally on the fact that the offering party gets elected. The $\mathrm{CB}$ accepts or refuses both grand-contracts being still uninformed on the state of the economy $\theta$.

$T=1:$ Ex ante collusion stage. If he has accepted the grand-contracts, the $\mathrm{CB}$ offers a side-contract to the interest group. This side-contract is now conditional on the electoral outcome.

$T=2$ : The electoral outcome realizes and the preferences of the political principal $\alpha_{i}$ are known by all players including the private sector of the economy which now forms its expectations on inflation.

Stages $T=3$ and 4 are then the same as with affiliated CBs.

Under political independence, the $\mathrm{CB}$ has thus the ability to commit to a side-contract with the anti-inflationist interest group before political uncertainty resolves. It is useful to already stress that this commitment ability is the source of the CB's own benefit from independence as we will see later.

Note that the sequence of events is such that the private sector knows precisely who gets elected before setting wage contracts. ${ }^{30}$ Also, in both cases, side-contracting takes place before the realization of the state of nature.

\subsection{A benchmark with complete information}

For future references, we derive the optimal monetary policy when a political principal with preferences $\alpha_{i}(i \in\{L, R\})$ has complete information on the realization of shocks, keeps full control on the monetary policy (i.e., does not rely on a $\mathrm{CB}$ ) and has the ability to commit to this policy before the private sector forms its expectations and negotiate wage contracts. Under complete information, the first best inflation targets,

\footnotetext{
${ }^{28}$ This timing captures in a simple way the enlarged opportunities for capture which are offered to the $\mathrm{CB}$ without having to consider a fully dynamic model. As we will see below, this shows already how budgets for independent $\mathrm{CB}$ must be increased to prevent the scope for capture.

${ }^{29}$ Invoking standard reputational arguments, we assume that those platforms are binding commitments once the elected principal comes to office.

${ }^{30}$ This assumption is thus in sharp contrast with Alesina and Gatti (1995) who argue that political uncertainty affects monetary policy when it is embodied into the private sector's expectations. We assume that wage contracts in the private sector are flexible enough to be changed just after elections. The only difference between the case of political independence and the case of political control comes thus from the nature of agency costs which will dramatically differ depending on the exact institutional setting.
} 
$\underline{\pi}_{i}^{\mathrm{FB}}$ and $\bar{\pi}_{i}^{\mathrm{FB}}$, offered by the elected political principal $i$ maximize expected welfare defined as

$$
\operatorname{Max}_{\left\{\underline{\pi}_{i}, \bar{\pi}_{i}\right\}} v\left(-\frac{\pi_{i}^{2}}{2}+\alpha_{i} \underline{\theta}\left(\underline{\pi}_{i}-\pi_{i}^{\mathrm{e}}\right)\right)+(1-v)\left(-\frac{\bar{\pi}_{i}^{2}}{2}+\alpha_{i}\left(\bar{\pi}_{i}-\pi_{i}^{\mathrm{e}}\right)\right)
$$

s.t.

$$
\pi_{i}^{\mathrm{e}}=v \underline{\pi}_{i}+(1-v) \bar{\pi}_{i} .
$$

Rewriting the principal's objective as a function of average inflation $\pi_{i}^{\mathrm{e}}$ and the difference in inflation targets $\Delta \pi_{i}=\bar{\pi}_{i}-\pi_{i}$, the principal's problem becomes

$$
\operatorname{Max}_{\left\{\pi_{i}^{\mathrm{e}}, \Delta \pi_{i}\right\}}-\frac{\left(\pi_{i}^{\mathrm{e}}\right)^{2}}{2}+v(1-v)\left(\alpha_{i} \Delta \theta \Delta \pi_{i}-\frac{\left(\Delta \pi_{i}\right)^{2}}{2}\right) .
$$

Since the political principal has the ability to commit to this policy rule, the optimal monetary policy entails no inflationary bias:

$$
\pi_{i}^{\mathrm{FBe}}=0 .
$$

The difference in inflation targets between both states of the world is thus

$$
\Delta \pi_{i}^{\mathrm{FB}}=\alpha_{i} \Delta \theta>0 .
$$

Greater concerns of the political principals for surprise inflation (i.e., $\alpha_{i}$ larger) increase therefore the variance of inflation $v(1-v)\left(\Delta \pi_{i}\right)^{2}$. Inflation is positive (resp. negative) $\bar{\pi}_{i}^{\mathrm{FB}}=v \alpha_{i} \Delta \theta$ (resp. $\left.\underline{\pi}_{i}^{\mathrm{FB}}=-(1-v) \alpha_{i} \Delta \theta\right)$ when a bad (resp. good) shock hits the economy. For further references, we observe that the political induced fluctuations in the variance of inflation depend only on the degree of polarization since

$$
\Delta \pi_{L}^{\mathrm{FB}}-\Delta \pi_{R}^{\mathrm{FB}}=\Delta \theta \Delta \alpha
$$

The commitment policy above has been extensively criticized for not being timeconsistent. In what follows, we investigate instead how this policy is robust to political pressures. Taking this perspective highlights that different institutional designs offer different responses to agency problems. It is not the lack of credibility that distorts the CB's incentives but the fact that the it may report excessively good news on the economy when it is captured by an anti-inflationist interest group who wants to avoid expansionary policies.

\section{Monetary policy under political control}

We now derive the second best inflation targets obtained when the political principal with preferences $\alpha_{i}$ is elected but relies on a privately informed, captured but affiliated $\mathrm{CB}$ to implement his most preferred monetary policy. 


\subsection{Collusion-proofness constraint}

To truthfully report, the $\mathrm{CB}$ must be sufficiently rewarded so that colluding with the anti-inflationist interest group becomes a dominated strategy. The grand-contract must thus satisfy a collusion-proofness constraint: ${ }^{31}$

$$
\bar{s}_{i}-\underline{s}_{i} \geqslant K\left(\beta \Delta \pi_{i}\right) .
$$

The left-hand side of (3.1) represents the wage differential necessary to prevent collusive behavior and to induce truthful announcement by the $\mathrm{CB}$. The right-hand side of (3.1) represents the benefits that the $\mathrm{CB}$ can pocket from his collusive relationship with the anti-inflationist interest group. This benefit takes into account the transaction costs dissipated in side-contracting.

Importantly, the collusion-proofness constraint derived above is a function of $\Delta \pi_{i}$ only. It depends thus only on the variance of inflation and not on its expectation. Henceforth, the nature of this collusion-proofness constraint is actually consistent with any timing for the formation of the private sector's expectations. The private sector can sign wage contracts indifferently before or after side-contracting has occurred without affecting the nature of the collusion-proofness constraint.

Finally, we assume thereafter that the following condition holds

Assumption 0. $k / r>\beta \alpha_{i} \Delta \theta$ for $i \in\{R, L\}$, so that the first best inflation targets yields a stake of capture belonging to the set of bribes where $K(\cdot)$ is increasing.

\subsection{Participation constraint}

The CB prefers to enter the public sector rather than getting an exogenous reservation utility normalized at zero. The following participation constraint must be satisfied:

$$
\underline{s}_{i} \geqslant 0 \text {. }
$$

Note that, when $\Delta \pi_{i}=\bar{\pi}_{i}-\underline{\pi}_{i}>0,(3.1)$ and (3.2) imply also that $\bar{s}_{i}>0$. This latter participation constraint can be omitted in what follows as long as the stake for collusion remains positive. To insure this, we assume that

Assumption 1. $k \beta<v \alpha_{i} \Delta \theta$ for $i \in\{R, L\} .{ }^{32}$

Finally, to guarantee concavity of the principals' problem when collusion is a concern, we also impose that

Assumption 2. $r \beta^{2}<v$.

\footnotetext{
${ }^{31}$ Tirole (1986) and Laffont and Tirole (1991, Chapter 11) prove that there is no loss of generality in restricting the principal to offer collusion-proof mechanisms in similar models.

${ }^{32}$ The principal will never find optimal to offer inflation targets such that $\Delta \pi_{i}$ is negative at the optimal contract. Indeed, when Assumption 1 does not hold, it is easy to see that the optimal contract entails $\underline{\pi}_{i}=\bar{\pi}_{i}=0$ and that there is no stake for collusion.
} 
Assumptions 0 and 2 are automatically satisfied when $r$ is small enough, i.e., when the transaction costs of side-contracting are small enough.

\subsection{Optimal inflation targets}

Under asymmetric information and the threat of capture, an optimal monetary policy proposed by principal $i$ must implement collusion-proofness at a minimal agency cost:

$$
A C_{i}^{\mathrm{PC}}\left(\Delta \pi_{i}\right)=\operatorname{Min}_{\left\{\underline{s}_{i}, \bar{s}_{i}\right\}} \underline{s}_{i}+(1-v) \bar{s}_{i}
$$

\section{s.t. (3.1) and (3.2).}

Both constraints are obviously binding, otherwise the principal could offer the same inflation targets and reduce at least one transfer to the $\mathrm{CB}$, increasing thereby his constituency's well-being. Note that the $\mathrm{CB}$ is thus rewarded when he announces that the economy faces a bad shock and chooses an expansionary policy since $\bar{s}_{i}>0$. Instead, when a good shock hits, the CB gets no reward. Intuitively, to fight capture the $\mathrm{CB}$ must be rewarded to announce news which hurt the interest group.

With political control, the agency cost associated with the delegation of monetary policy to the $\mathrm{CB}$ writes thus as

$$
A C_{i}^{\mathrm{PC}}\left(\Delta \pi_{i}\right)=(1-v) K\left(\beta \Delta \pi_{i}\right) .
$$

The optimal collusion-proof monetary policy with an affiliated CB solves

$$
\operatorname{Max}_{\left\{\pi_{i}^{\mathrm{e}}, \Delta \pi_{i}\right\}}-\frac{\left(\pi_{i}^{\mathrm{e}}\right)^{2}}{2}+v(1-v)\left(\alpha_{i} \Delta \theta \Delta \pi_{i}-\frac{\left(\Delta \pi_{i}\right)^{2}}{2}\right)-A C_{i}^{\mathrm{PC}}\left(\Delta \pi_{i}\right) .
$$

We index with a superscript PC meaning political control this optimal policy. Direct optimization yields immediately

Proposition 1. Assume that Assumptions 1 and 2 both hold. Under asymmetric information and political control, the optimal collusion-proof monetary policy offered by a political principal with preferences $\alpha_{i}$ entails:

-No inflationary bias

$$
\pi_{i}^{\mathrm{PCe}}=0 .
$$

-The difference in inflation targets is

$$
\Delta \pi_{i}^{\mathrm{PC}}=\frac{\alpha_{i} \Delta \theta-k \beta / v}{1-r \beta^{2} / v} \cdot{ }^{33}
$$

-The variance of inflation is positive but lower than under complete information since

$$
0<\Delta \pi_{i}^{\mathrm{PC}}<\Delta \pi_{i}^{\mathrm{FB}} .
$$

No inflationary bias: The threat of capture of the central bank does not affect the ability of political principals to avoid any inflationary bias. Even if it is somewhat

\footnotetext{
${ }^{33}$ In the absence of any collusion $(k=r=0)$ the first best monetary policy is still implemented.
} 
undermined by asymmetric information, delegating monetary policy to a CB before the private sector forms its expectations still helps the elected political principal to commit and to correct ex post incentives for surprise inflation. Of course, this contract is now affected by the principal's desire to avoid the capture of monetary policy. Nevertheless, solving the collusion problem does not conflict with maintaining credibility.

Variance of inflation: Comparing (2.4) with (3.3), we observe that delegation of monetary policy to a better informed $\mathrm{CB}$ requires to reduce the variance of inflation. The outcome of the political process is such that the political principal looks more inflation averse than what he really is. Indeed, the policy outcome is exactly the same as if the political principal runs himself the monetary policy, gets perfect information on the macroeconomic shock but had his preference parameter $\alpha_{i}$ being replaced with $\alpha_{i}^{\prime}(\beta)$ such that

$$
\alpha_{i}^{\prime}(\beta)=\alpha_{i}\left(\frac{1-k \beta / v \alpha_{i} \Delta \theta}{1-r \beta^{2} / v}\right)<\alpha_{i},
$$

where the right-hand side inequality follows from Assumptions 0 and 2. Everything happens thus as if the preferences of the anti-inflationist interest groups were somewhat embodied into the preferences of the political principals. Anticipating the political pressures for stringent monetary policies, the principal behaves as being more inflation-averse. The fact that monetary policy looks like being implemented by a more inflation-averse government does not come from any bias for low inflation in the CB's preferences but from the fact that the monetary policy must satisfy a collusionproofness constraint which appears endogenously in a framework with asymmetric information.

By reducing the variance of inflation below its first best value, the political principal reduces the stake of collusion with an anti-inflationist interest group. Information on economic shocks is thus obtained at a lower cost. The right-hand side of (3.1) is reduced and the socially costly wage given to the $\mathrm{CB}$ to satisfy this constraint diminishes. Of course, since a leftist party is more prone to run an expansionary policy, it offers large collusive stake and suffers thereby more from the threat of capture by an anti-inflationist interest group.

Comparative statics: Interestingly, $\alpha_{i}^{\prime}(\beta)$ decreases with $\beta .{ }^{34}$ The political principal commits to a more conservative policy when the anti-inflationist interest group has more pronounced preferences for surprise deflation. As a result, the optimal variance of inflation decreases also with $\beta$. The threat of capture calls for less fluctuations in inflation than the first best policy as the anti-inflationist interest group becomes more powerful. Indeed, those groups have then more influence on the $\mathrm{CB}$ and the stake for capture increases. This makes collusion-proofness more costly for the political principal. Decreasing the variance of inflation prevents thus capture in a less costly way. We note

\footnotetext{
${ }^{34}$ One has indeed: $\partial \alpha_{i}^{\prime}(\beta) / \partial \beta=\left(-k v-k r \beta^{2}+2 v r \beta \alpha_{i} \Delta \theta\right) /\left(v-r \beta^{2}\right)^{2}$. But the numerator is increasing in $\beta$ for $\beta<\beta_{m}=v \alpha_{i} \Delta \theta / k$ as specified in Assumption 1. Its maximal value is worth $-v+r \beta_{m}^{2}$ which is negative when Assumption 2 holds.
} 
also that

$$
\begin{aligned}
\Delta \pi_{L}^{\mathrm{PC}}-\Delta \pi_{R}^{\mathrm{PC}} & =\left(\alpha_{L}^{\prime}(\beta)-\alpha_{R}^{\prime}(\beta)\right) \Delta \theta \\
& =\Delta \theta \Delta \alpha\left(\frac{1}{1-r \beta^{2} / v}\right)>\Delta \pi_{L}^{\mathrm{FB}}-\Delta \pi_{R}^{\mathrm{FB}} .
\end{aligned}
$$

This latter equality shows that the possibility of capture increases the political induced fluctuations in the variance of inflation.

Finally, a greater value of $r$ increases also the optimal choice of the variance of inflation made by the political principals. Indeed, when $r$ increases, collusion becomes less efficient. Both political principals find it less valuable to reduce the variance of inflation to fight capture which is less of a concern. Their objectives become more dissonant and the politically induced fluctuations in the variance of inflation also increase.

The social planner outcome: Had a social planner been ruling monetary policy with the help of a possibly captured $\mathrm{CB}$, the variance of inflation would still be given by formula (3.3) but with $\hat{\alpha}$ replacing $\alpha_{i}$. The corresponding standard deviation in inflation target is exactly the average of those under partisanship since

$$
\Delta \pi_{\hat{\alpha}}=p \Delta \pi_{R}^{\mathrm{PC}}+(1-p) \Delta \pi_{L}^{\mathrm{PC}} .
$$

Political uncertainty creates thus some politically induced fluctuations in monetary policy around the middle-road policy which would be proposed by a social planner who would be controlling a possibly captured CB. We will see that those fluctuations are in fact significantly reduced when political independence is granted to the $\mathrm{CB}$.

\section{Inflation stabilization under political independence}

The politically independent CB implements now the monetary policy for both elected principals. He now benefits from this political independence to offer a side-contract to the anti-inflationist interest group even before political uncertainty is resolved.

\subsection{Ex ante collusion}

Side-contracting takes now place ex ante and this is the expected stake of capture when $\bar{\theta}$ realizes, namely $\beta\left(p \Delta \pi_{R}+(1-p) \Delta \pi_{L}\right)$, which matters to characterize the maximal bribe that the anti-inflationist group is ready to give up to the $\mathrm{CB}$ to make him lie on his announcement of the economic shock. To prevent this ex ante collusion, both political principals must collectively offer policy platforms giving an expected wage to the $\mathrm{CB}$ which is greater than what he may obtain from side-contracting. The corresponding ex ante collusion-proofness constraint writes thus as

$$
p\left(\bar{s}_{R}-\underline{s}_{R}\right)+(1-p)\left(\bar{s}_{L}-\underline{s}_{L}\right) \geqslant K\left(\beta\left(p \Delta \pi_{R}+(1-p) \Delta \pi_{L}\right)\right) .
$$

Of course, the CB could also wait for the outcome of the election before offering any side-contract at all and enter into ex post collusions which would look alike those 
considered in Section 3. However, the CB strictly prefers to commit to a side-contract before political uncertainty resolves. Indeed, because the efficiency of side-contracting $K(\cdot)$ is a strictly concave function of the collusive stake, we always have

$$
K\left(\beta\left(p \Delta \pi_{R}+(1-p) \Delta \pi_{L}\right)\right)>p K\left(\beta \Delta \pi_{R}\right)+(1-p) K\left(\beta \Delta \pi_{L}\right) .
$$

We have already seen that (3.1) is binding at the optimal contract with ex post side-contracting. Hence, for a given pair of monetary policies $\left(\left\{\bar{\pi}_{R}, \underline{\pi}_{R}\right\},\left\{\bar{\pi}_{L}, \underline{\pi}_{L}\right\}\right)$, the right-hand side above represents the expected wages to be given to the $\mathrm{CB}$ if side-contracts occur only ex post. Political independence, since it allows ex ante sidecontracting, makes thus collusion between the $\mathrm{CB}$ and the interest group harder to prevent.

Only the expectations of the wage differentials $\bar{s}_{i}-\underline{s}_{i}(i \in\{R, L\})$ is determined when the ex ante collusion-proofness constraint (4.1) is binding as it will be the case in equilibrium. However, since the left-hand side of (4.2) is strictly greater than the right-hand side, it is possible to find values of $\bar{s}_{R}-\underline{s}_{R}$ and $\bar{s}_{L}-\underline{s}_{L}$ such that both ex post collusion-proofness constraints (3.1) are strictly satisfied at the Nash equilibrium between both parties. Ex ante collusion-proofness implies thus ex post collusion-proofness. This means that, even if the collusive partners cannot commit not to collude ex post, i.e., once the political principal is elected, this collusion will not matter, since it will not be beneficial to the $\mathrm{CB}$ anyway.

\subsection{Equilibrium inflation targets}

Platforms on monetary policies are now offered non-cooperatively by both parties before the elections. We are thus looking for a Nash equilibrium between the two possible political principals of a common bureaucracy. Taking as given the wages and the inflation targets promised by the leftist government, the optimal monetary policy offered by the rightist government implements collusion-proofness at minimal cost when it solves

$$
A C_{R}^{\mathrm{PI}}\left(\Delta \pi_{R}\right)=\operatorname{Min}_{\left\{\underline{s}_{R}, \bar{s}_{R}\right\}} v \underline{s}_{R}+(1-v) \bar{s}_{R}
$$

s.t. (4.1) and (3.2).

Both constraints are again binding and the agency cost borne by the rightist government under political independence writes thus as

$$
A C_{R}^{\mathrm{PI}}\left(\Delta \pi_{R}\right)=\frac{1}{p}(1-v)\left(K\left(\beta\left(p \Delta \pi_{R}+(1-p) \Delta \pi_{L}\right)\right)-(1-p)\left(\bar{s}_{L}-\underline{s}_{L}\right)\right) .
$$

The monetary policy offered when the CB benefits from political independence solves

$$
\operatorname{Max}_{\left\{\pi_{R}^{\mathrm{e}}, \Delta \pi_{R}\right\}}-\frac{\left(\pi_{R}^{\mathrm{e}}\right)^{2}}{2}+v(1-v)\left(\alpha_{R} \Delta \theta \Delta \pi_{R}-\frac{\left(\Delta \pi_{R}\right)^{2}}{2}\right)-A C_{R}^{\mathrm{PI}}\left(\Delta \pi_{R}\right) .
$$

The following proposition characterizes the Nash equilibrium of this game. We index with a superscript PI meaning political independence of these policies. 
Proposition 2. Assume that Assumptions 1 and 2 both hold. Under asymmetric information and political independence, there exists a unique Nash equilibrium between the political principals with (4.1) being binding. The equilibrium monetary policy offered by a political principal with preferences $\alpha_{i}$ entails:

-No inflationary bias

$$
\pi_{i}^{\mathrm{PIe}}=0 .
$$

-If political principal $i$ gets elected, the difference in the inflation targets chosen by the $C B$ is

$$
\Delta \pi_{R}^{\mathrm{PI}}=\frac{\alpha_{R} \Delta \theta-k \beta / v+\left(r \beta^{2} / v\right)(1-p) \Delta \theta \Delta \alpha}{1-r \beta^{2} / v}
$$

and

$$
\Delta \pi_{L}^{\mathrm{PI}}=\frac{\alpha_{L} \Delta \theta-k \beta / v-\left(r \beta^{2} / v\right) p \Delta \theta \Delta \alpha}{1-r \beta^{2} / v}
$$

-Moreover, the variance of inflation is reduced under political independence and we have

$$
\Delta \pi_{R}^{\mathrm{PC}}<\Delta \pi_{R}^{\mathrm{PI}}<\Delta \pi_{L}^{\mathrm{PI}}<\Delta \pi_{L}^{\mathrm{PC}}
$$

with

$$
p \Delta \pi_{R}^{\mathrm{PI}}+(1-p) \Delta \pi_{L}^{\mathrm{PI}}=p \Delta \pi_{R}^{\mathrm{PC}}+(1-p) \Delta \pi_{L}^{\mathrm{PC}}=\Delta \pi_{\hat{\alpha}}
$$

Stabilization of the variance of inflation: Comparing (3.3) with (4.3) and (4.4), we observe that the variance of inflation is significantly affected by the legal status of the CB. Under political independence, a rightist (resp. leftist) government increases (resp. decreases) the variance of inflation and looks now much more alike a leftist (resp. rightist) government. Indeed, increasing $\Delta \pi_{R}$ by $\varepsilon$ increases the agency cost of delegation borne by the rightist government by an amount $(1-v) \varepsilon K^{\prime}\left(p \Delta \pi_{R}+(1-\right.$ $\left.p) \Delta \pi_{L}\right)$. Since a leftist government is more willing to create surprise inflation than a rightist one, we have $\Delta \pi_{R}<\Delta \pi_{L}$ so that the right-hand side above is smaller than $(1-v) \varepsilon K^{\prime}\left(\Delta \pi_{R}\right)$ since $K(\cdot)$ is concave. This last term is in fact the marginal agency cost incurred by the elected rightist government when it increases by $\varepsilon$ the variance of inflation, the $\mathrm{CB}$ is under its political control and collusion occurs thus only ex post. Therefore, the rightist government is more willing to implement an expansionary policy under political independence since the marginal agency cost of delegation decreases from its point of view. Similarly but for the reverse reasons, the leftist government's willingness to decrease the variance of inflation increases under political independence. As a result, the leftist government looks like a more inflation-averse government than what it really is. In both cases, everything happens as if the political principal had his preferences $\alpha_{i}$ being modified to incorporate not only the pressure of interest groups as in Section 3 but also the political strength of the non-elected minority. For a rightist 
government, $\alpha_{R}^{\prime}(\beta)$ is now replaced by $\alpha_{R}^{\prime \prime}(\beta)$ such that

$$
\alpha_{R}^{\prime \prime}(\beta)=\alpha_{R}\left(\frac{1-k \beta / v \alpha_{R} \Delta \theta+r \beta^{2}(1-p) \Delta \alpha / v \alpha_{R}}{1-r \beta^{2} / v}\right)>\alpha_{R}^{\prime}(\beta) .
$$

For a leftist government, $\alpha_{L}^{\prime}(\beta)$ is replaced with $\alpha_{L}^{\prime \prime}(\beta)$ such that

$$
\alpha_{L}^{\prime \prime}(\beta)=\alpha_{L}\left(\frac{1-k \beta / v \alpha_{L} \Delta \theta-r \beta^{2} p \Delta \alpha / v \alpha_{L}}{1-r \beta^{2} / v}\right)<\alpha_{L}^{\prime}(\beta) .
$$

That the preferences of the non-elected minority get now somewhat embodied into the actual policy outcome is directly implied by the fact that the ex ante collusion-proofness constraint makes the actual agency costs borne by the elected majority depend also on the policy which would have been implemented if the minority had instead been elected.

When collusion matters, political independence ensures therefore the convergence of partisan monetary policies towards the socially optimal level of inflations implemented by a social planner. Keeping the same average variance of inflation than under political control (see (4.6)), the independent CB stabilizes the politically induced fluctuations in the variance of inflation. Indeed, comparing the variances of inflation under both legal regimes yields

$$
\Delta \pi_{L}^{\mathrm{PI}}-\Delta \pi_{R}^{\mathrm{PI}}=\Delta \pi_{L}^{\mathrm{FB}}-\Delta \pi_{R}^{\mathrm{FB}}=\Delta \theta \Delta \alpha<\Delta \pi_{L}^{\mathrm{PC}}-\Delta \pi_{R}^{\mathrm{PC}}=\frac{\Delta \theta \Delta \alpha}{1-r \beta^{2} / v} .
$$

The extra politically induced fluctuations in the variance of inflation introduced by the possibility of capture are now eliminated. With independence, we find back the first best political fluctuations in monetary policy.

Note that the parameter $\beta$, i.e., the intensity of the anti-inflationist interest group's preferences for surprise deflation, does not affect those politically induced fluctuations under independence, contrary to the case of affiliated CBs where those fluctuations increases with $\beta$. The stabilization in the politically induced fluctuations of inflation becomes more significant as the preferences of interest groups are more pronounced.

According to our results, countries with independent CB should have less inflation volatility than countries with politically controlled central banks. This fact has received some empirical back up. In a cross-sectional countries empirical analysis, Cecchetti et al. (2001) compare the 1980 s to the 1990 s which witnessed the trend toward central banks independence. They observe that inflation volatility has fallen markedly while output variability has either fallen or risen only slightly. These authors show that this increased stability is essentially explained by more efficient monetary policies. Once one controls for the magnitudes of the shocks hitting each economy, Cecchetti and Ehrmann (2002) also show that independent (inflation targeting) CBs achieve less inflation volatility for a given level of output volatility. Cukierman (1998, Chapter 22) deals with the well-known positive correlation between the mean and the variance of inflation. For a cross section of countries, his results suggest that at least a seventh of this correlation between the mean and the standard deviation of inflation is due to variations in the degree of $\mathrm{CB}$ independence. 
Comparative statics: The rightist (resp. leftist) government has more incentives to increase (resp. decrease) the variance of inflation and thus to look more like a leftist (resp. rightist) government when the probability that he does not get elected increases. Even if it turns out that it does not get elected, the party which has the greatest probability of coming to power sees the monetary policy being significantly shifted towards the monetary policy it would have implemented had the CB been under its full control.

With a rightist (resp. leftist) government, the size of this upwards (resp. downwards) shift in the variance of inflation depends also on the degree of political polarization. Quite intuitively, more polarization calls also for adding greater corrective terms (resp. $r \beta^{2}(1-p) \Delta \theta \Delta \alpha /\left(v-r \beta^{2}\right)$ for a rightist government and $-r \beta^{2} p \Delta \theta \Delta \alpha /\left(v-r \beta^{2}\right)$ for a leftist one) to the optimal standard deviation of inflation implemented under political control to get its value with political independence. More polarization implies indeed more politically induced fluctuations of inflation both when the $\mathrm{CB}$ is under political control and when he is independent as it can be seen in (4.7). However, those fluctuations in the variance of inflation are smaller in the case of political independence.

A greater value of $r$ increases also the size of the corrective terms appearing under political independence. When $r$ is greater, transaction costs of side-contracting are greater and political principals do not reduce so much the variance of inflation to prevent collusion. The politically induced fluctuations of inflation remain quite large and the stabilization of monetary policies achieved under political independence is more valuable.

\section{Ex ante welfare and constitutional design}

Granting political independence to the CB clearly affects ex ante welfare since it changes the inflation targets which are implemented. To better assess the welfare consequences of the CB's independence, we now isolate two effects which are at work simultaneously. First, as shown by (4.2), the same inflation targets would be implemented at a higher expected agency cost under political independence than with political control. This delegation effect is clearly a social cost of political independence. Political independence makes capture of the CB more costly for society. Second, assuming that agency costs would be the same with both legal status, i.e., assuming that, with political independence, the agency costs would still be computed with the ex post collusion-proofness constraints, social welfare would increase with political independence since inflation targets are now better stabilized around their socially optimal values and social welfare is a concave function. This captures the stabilization effect of political independence.

To better assess the size of these two effects and to determine which ends up dominating, we now rewrite social welfare in regime PC and when party $i$ has been elected. Indeed, taking into account the expressions of the CB's wages obtained when (3.1) and (3.2) are both binding, expected social welfare when party $i$ gets elected writes as a function of $\Delta \pi_{i}^{\mathrm{PC}}$ only:

$$
S W\left(\Delta \pi_{i}^{\mathrm{PC}}\right)=v(1-v)\left(\left(\hat{\alpha} \Delta \theta-\frac{k \beta}{v}\right) \Delta \pi_{i}^{\mathrm{PC}}-\frac{1}{2}\left(1-\frac{r \beta^{2}}{v}\right)\left(\Delta \pi_{i}^{\mathrm{PC}}\right)^{2}\right) .
$$


Under political control, the expected social welfare writes thus as

$$
S W^{\mathrm{PC}}=p S W\left(\Delta \pi_{R}^{\mathrm{PC}}\right)+(1-p) S W\left(\Delta \pi_{L}^{\mathrm{PC}}\right) .
$$

Under political independence, agency costs take a different expression than under political control. Taking into account this difference, expected social welfare under independence writes instead as

$$
\begin{aligned}
S W^{\mathrm{PI}}= & \left(p S W\left(\Delta \pi_{R}^{\mathrm{PI}}\right)+(1-p) S W\left(\Delta \pi_{L}^{\mathrm{PI}}\right)\right) \\
& +(1-v)\left(p K\left(\beta \Delta \pi_{R}^{\mathrm{PI}}\right)+(1-p) K\left(\beta \Delta \pi_{L}^{\mathrm{PI}}\right)\right. \\
& -K\left(\beta\left(p \Delta \pi_{R}^{\mathrm{PI}}+(1-p) \Delta \pi_{L}^{\mathrm{PI}}\right)\right) .
\end{aligned}
$$

The first parentheses above is greater than the right-hand side of (5.1) capturing the stabilization effect. The second parentheses represents the difference in agency costs between independence and political control when the agency cost under political control is computed with the inflation targets obtained under independence. This delegation effect is obviously negative from the concavity of $K(\cdot)$. The capture of the $\mathrm{CB}$ is indeed more costly under political independence. Comparing both legal status of the $\mathrm{CB}$, we define

$$
\Delta S W=S W^{\mathrm{PI}}-S W^{\mathrm{PC}} .
$$

Proposition 3. From an ex ante social point of view, political independence is the best response to the threat of capture by anti-inflationist interest groups in a world of political uncertainty. Moreover, we have

$$
\Delta S W=\frac{v(1-v)}{2} p(1-p)(\Delta \alpha)^{2}(\Delta \theta)^{2}\left(\frac{r \beta^{2}}{v-r \beta^{2}}\right)>0 .
$$

On the one hand, political independence reduces the politically induced fluctuations of inflation but do so by still preserving the mean $\Delta \pi_{\hat{\alpha}}$ of $\Delta \pi_{i}$. On the other hand, political independence increases the agency cost of delegation. Nevertheless, the first stabilization effect always dominates and political independence should be granted to the $\mathrm{CB}$.

With political independence, the non-elected minority is better protected since the monetary policy chosen by the independent $\mathrm{CB}$ is closer to what would be chosen by the minority itself. A politically independent $\mathrm{CB}$ acts thus as a safeguard against expropriation of the minority by the elected majority. The best institutional choice gives more freedom to the independent $\mathrm{CB}$ and this plays against biased political principals.

The difference in ex ante social welfare between both legal status of the CB increases when the technology of side-contracting is rather bad ( $r$ getting larger). As a consequence, any administrative rule hardening the collusion between the $\mathrm{CB}$ and anti-inflationist interest groups (so that the latter is better insulated from the influence of this group) makes also the political independence of the $\mathrm{CB}$ be more valuable. 
There exists a complementarity between the legal status of the central bank and those administrative rules. An example of such rules is a restriction on the length of the CB's tenure. Another can be to separate banking supervision from monetary policy so that the transaction costs of collusion between the CB and the financial sector increases.

Similarly, more polarization ( $\Delta \alpha$ being greater) and more political variance $(p(1-p)$ being greater) mean also a greater difference between the monetary policies implemented by rightist and leftist governments. This exacerbated discrepancy between the most preferred monetary policies of both parties increases both the stabilization and the delegation effect. The benefits of granting political independence to the $\mathrm{CB}$ are greater as political uncertainty increases. As a consequence, this independence is more beneficial in countries with coalitional governments since the latters are more likely to change and are characterized by higher political uncertainty.

Once elected, both biased principals dislike CB's political independence since it forces them to move monetary policy towards that of the minority. The independent CB's ability to commit to ex ante collusion nevertheless significantly stabilizes policies and make these policies less sensitive to the exact identity of the political principal who finally gets elected. This stabilization may be good from an ex ante social welfare point of view as we have just seen in Proposition 3. To some extent, it may even be desirable for ideological biased principals before the election takes place: If they lose, their rival will implement a policy less different from what they would have done themselves. Indeed, since expected welfare is greater with political independence, there exist simple ex ante transfers which make both political principals benefit from the gains of stabilization. Of course, the relative gain of each of these principals may depend on the bargaining power of each constituency at the ex ante stage when the constitution is designed. In particular, if the design of the central bank charter is made by one of the partisan principals himself, he may be able to grasp most of the benefits from this independence. ${ }^{35}$

\section{Pro-inflationist interest groups}

Pro-inflationist interest groups are diverse. They may be employers who have an incentive to favor surprise inflation to pay lower real wages, small businessmen, farmers and borrowers who also benefit from surprise inflation when loan contracts are expressed in nominal terms. Insiders may be particular for reelection concerns, subgroups of Congressmen may also invest in information gathering and lobby accordingly for more expansionary monetary policies than what the median uninformed political principal wants to implement. Taking the view that the central bank is

\footnotetext{
${ }^{35} \mathrm{We}$ should note the difference between this discussion and Alesina and Gatti (1995). In the latter paper, both political principals must agree on the design of the degree of inflation aversion for the $\mathrm{CB}$ in a model à la Rogoff (1985) and they do so through ex ante bargaining reflecting their strengths at the constitutional stage. Here, the agreement between both parties occurs also ex ante but consists of lump-sum transfers only. Ex post, the control of the $\mathrm{CB}$ and the design of his incentive package is left to whoever gets elected.
} 
actually a committee, those interest groups can also be seen as particular members trying to influence the head of the agency. ${ }^{36}$ This view can be particularly relevant in the case of central banks having regional representation where some regions can prefer looser monetary policy. ${ }^{37}$ In the context of European monetary policy, countries have different preferences about inflation and some countries may be tempted to influence the ECB's monetary policy if they benefit from more expansionary policies. Of course, the status of the ECB explicitly forbids any representative of the European Council to be part of the ECB's Council (Art. 15.1) but does not forbid the informal presence of EEC Officials at Board Meetings. ${ }^{38}$

Such a pro-inflationist interest group can easily be included into the analysis. To do so, suppose that such a group has utility $A I=\gamma \theta\left(\pi-\pi_{\mathrm{e}}\right)$ for some positive parameter $\gamma$. When a bad shock hits the economy, the pro-inflationist interest group opposes to the incentives of anti-inflationist interest group which want to make the central banker lie on the state of nature. The stake for doing so is $\gamma \Delta \pi_{i}$ when the political principal $i$ is elected. Without entering into the details of the bargaining procedure between the $\mathrm{CB}$ and the interest groups, it should be clear that the $\mathrm{CB}$ cannot receive more bribes than $(\beta-\gamma) \Delta \pi_{i}$. Intuitively, the CB must leave to the pro-inflation interest group the amount $\gamma \Delta \pi_{i}$ to avoid that the latter behaves as a whistle-blower and report to the government the true state of nature $\bar{\theta}$. Consequently, the collusion-proofness constraint is relaxed and can be written as

$$
\bar{s}_{i}-\underline{s}_{i} \geqslant K\left((\beta-\gamma) \Delta \pi_{i}\right) .
$$

Of course, the previous equation is valid as long as the anti-inflationist groups are more powerful than pro-inflationists ones, i.e., $\beta>\gamma$. The analysis we made previously goes through with $\beta^{\prime}=\beta-\gamma$ replacing $\beta$ everywhere. The presence of a countervailing interest group reduces the political induced fluctuations of capture and reduces therefore the benefits of granting independence to the CB. Independence is less likely to occur when anti-inflationist interest groups are more powerful.

If pro-inflationist interest groups are more powerful than the anti-inflationist ones, the $\mathrm{CB}$ would have no incentive to report a good shock when $\bar{\theta}$ realizes. Instead, when only the good state of the economy $\underline{\theta}$ can be manipulated and reported to be worse than what it really is by the $\mathrm{CB}$, collusion between the $\mathrm{CB}$ and the dominant pro-inflationist interest group matters. One needs to introduce a collusion-proofness constraint of the form

$$
\underline{s}_{i}-\bar{s}_{i} \geqslant K\left((\gamma-\beta) \Delta \pi_{i}\right) .
$$

\footnotetext{
${ }^{36}$ For instance, Faust (1996) argues that members of a CB's committee are heterogenous with respect to the distributive consequences of surprise inflation. Toma (1982) also recognizes the heterogeneity of interest groups influencing the FED's decision-making and defends the view that the political process is dominated by forces pushing to increase money supply.

${ }^{37}$ In the U.S., monetary policy is made by the Federal Open Market Committee (FOMC) consisting of the governors of the Federal Reserve System, nominated by the President of the U.S. and five Presidents of regional Reserve Banks on a rotating basis.

${ }^{38}$ The mere fact that Art. 7 of the status of the ECB precludes ECB's board members from receiving explicit recommendations from national political institutions can be viewed as setting up constraints reducing capture by national interest groups.
} 
Without doing the complete analysis, it should first be clear that preventing collusion requires now to give a reward to the $\mathrm{CB}$ in the good state of nature. The capture of the $\mathrm{CB}$ also implies that political principals choose a policy $\Delta \pi_{i}^{\mathrm{PC}}$ which is again smaller than $\Delta \pi_{i}^{\mathrm{FB}}$ to counter the pro-inflationist political pressures on the $\mathrm{CB}$. The politically induced fluctuations in monetary policy are still expressed as in (3.5) but with $v$ replacing now $1-v$ since the manipulation takes place in state $\underline{\theta}$. Finally, it is easy to check that the stabilization and delegation effects are also unchanged. The welfare analysis made in Section 5 remains valid and justifies also independence of the $\mathrm{CB}$.

\section{Conclusion}

This paper has shown that different legal status of a $\mathrm{CB}$ are in fact associated with different opportunities for capture of the monetary policy by interest groups. The degree of political independence affects thus the agency costs paid to control the $\mathrm{CB}$. An independent $\mathrm{CB}$ helps to stabilize the politically induced fluctuations of inflation but the agency costs of delegating monetary policy to such a CB increases also when the latter is granted political independence. Nevertheless, ex ante social welfare increases with political independence. This comes from the fact that the politically induced fluctuations due to agency costs are better stabilized by an independent $\mathrm{CB}$.

Several extensions of our framework could be discussed. First, it would be particularly interesting to analyze in our contracting framework how granting long-term tenures to CBs improves ex ante social welfare but may be costly when general economic conditions (like the distribution of shocks affecting the economy or the preferences of the agents) may change over time. ${ }^{39}$ Second, in our analysis, we have taken the probabilities that both parties get elected as purely exogenous. This has allowed us to explain the optimal choice of institutions for monetary policy in a world of political uncertainty. However, these probabilities could be endogenized and could thus depend on the monetary policies proposed by both parties before the elections. As we have seen, those political platforms are themselves significantly affected by the legal status of the CB. Such an extension of the model would also allow us to analyze the interesting feedback that institutions have on the electoral outcomes. The amount of political uncertainty and the institutional choice would thus be derived simultaneously. Finally, it should be stressed that our model could also be extended to the case where principals have no ability to commit to their incentive contracts. Our comparison between independence and political control would also be meaningful in this framework.

\section{Acknowledgements}

We thank Christian Bordes, Jean-Jacques Laffont, two referees and the Editor Jordi Gali for their insightful comments. All errors are ours.

\footnotetext{
${ }^{39}$ See Waller and Walsh (1996) for a related model.
} 


\section{Appendix}

Proof of Proposition 2. Under Assumption 2, the objective function remains concave with respect to $\Delta \pi_{R}$. of course, $\pi_{\mathrm{e}}^{\mathrm{PI}}=0$ at the optimum. Optimizing with respect to $\Delta \pi_{R}$ yields immediately the linear relationship characterizing the best response of the rightist government:

$$
\left.v\left(\alpha_{R} \Delta \theta-\Delta \pi_{R}\right)=k \beta-r \beta^{2}\left(p \Delta \pi_{R}+(1-p) \Delta \pi_{L}\right)\right) .
$$

Doing similarly for the leftist party, we would have

$$
\left.v\left(\alpha_{L} \Delta \theta-\Delta \pi_{L}\right)=k \beta-r \beta^{2}\left(p \Delta \pi_{R}+(1-p) \Delta \pi_{L}\right)\right) .
$$

Solving this linear system yields the values of the Nash equilibrium variance of inflation targets.

Proof of Proposition 3. We have $\Delta S W=S W^{\mathrm{PI}}-S W^{\mathrm{PC}}=A+B$ where $A$ represents the stabilization effect and $B$ the agency effect. After some computations, we easily find that

$$
\begin{aligned}
A & =p S W\left(\Delta \pi_{R}^{\mathrm{PI}}\right)+(1-p) S W\left(\Delta \pi_{L}^{\mathrm{PI}}\right)-\left(p S W\left(\Delta \pi_{R}^{\mathrm{PC}}\right)+(1-p) S W\left(\Delta \pi_{L}^{\mathrm{PC}}\right)\right) \\
& =\frac{v(1-v)}{2}\left(1-\frac{r \beta^{2}}{v}\right)\left(\operatorname{Var}\left(\Delta \pi_{i}^{\mathrm{PC}}\right)-\operatorname{Var}\left(\Delta \pi_{i}^{\mathrm{PI}}\right)\right),
\end{aligned}
$$

where $\operatorname{Var}(\cdot)$ denotes the variance operator. After computations, we find for the stabilization effect:

$$
A=\frac{v(1-v)}{2} p(1-p)(\Delta \alpha)^{2}(\Delta \theta)^{2}\left(\frac{\left(r \beta^{2} / v\right)\left(2-r \beta^{2} / v\right)}{1-r \beta^{2} / v}\right)>0 .
$$

We have also for the delegation effect:

$$
\begin{aligned}
B & =(1-v)\left(p K\left(\beta \Delta \pi_{R}^{\mathrm{PI}}\right)+(1-p) K\left(\beta \Delta \pi_{L}^{\mathrm{PI}}\right)-K\left(\beta\left(p \Delta \pi_{R}^{\mathrm{PI}}+(1-p) \Delta \pi_{L}^{\mathrm{PI}}\right)\right)\right. \\
& =-\frac{v(1-v)}{2}\left(\frac{r \beta^{2}}{v}\right) \operatorname{Var}\left(\Delta \pi_{i}^{\mathrm{PI}}\right)=-\frac{v(1-v)}{2} p(1-p)(\Delta \alpha)^{2}(\Delta \theta)^{2}\left(\frac{r \beta^{2}}{v}\right)<0 .
\end{aligned}
$$

Summing both effects yields Proposition 3.

\section{References}

Alesina, A., Gatti, R., 1995. Independent central banks: Low inflation at no cost? American Economic Review 85 (2), 196-200. 
Barro, R., Gordon, D., 1983. A positive theory of monetary policy in a natural rate model. Journal of Political Economy 31, 589-610.

Beck, N., 1987. Elections and the fed: Is there a political monetary cycle. American Journal of Political Science 31, 194-216.

Blinder, A., 1999. Central Banking in Theory and Practice. MIT Press, Cambridge, MA.

Cecchetti, S., Ehrmann, M., 2002. Does inflation targeting increases output volatility? An international comparison of policymakers' preferences and outcomes. In: Loayza, N., Schmidt-Hebbel, K. (Eds.), Monetary Policy: Rules and Transmission Mechanisms. Central Bank of Chile, Santiago.

Cecchetti, S., Flores-Lagunes, A., Krause, S., 2001. Has monetary policy become more efficient. NBER Working paper.

Cukierman, A., 1998. Central Bank Strategy, Credibility and Independence. MIT Press, Cambridge, MA.

Cukierman, A., Meltzer, A., 1986. A theory of ambiguity, credibility and inflation under discretion and asymmetric information. Econometrica 54, 1099-1128.

Dixit, A., 1998. Equilibrium contracts for the European central banker. Mimeo., Princeton University.

Faure-Grimaud, A., Martimort, D., 2000. Political stabilization by an independent bureaucracy. Mimeo., IDEI Toulouse.

Faust, J., 1996. Whom can we trust to run the Fed? Theoretical support for the founder's view. Journal of Monetary Economics 37, 267-283.

Friedman, M., 1962. Should there be an Independent Monetary Authority? Dollars and Deficit. Prentice-Hall, Englewood Cliffs, NJ, 1968 (reprinted).

Friedman, M., 1972. The case for a monetary rule. Newsweek, December 8.

Froyen, R., Havrilesky, T., Waud, R., 1993. Political and special interest pressures on U.S. monetary policy. Mimeo., University of North Carolina.

Garfinkel, M., Glazer, A., 1994. Does electoral uncertainty cause economic fluctuations. American Economic Review 84 (2), 169-173.

Grilli, V., Masciandaro, D., Tabellini, G., 1991. Political and monetary institutions and public finance policies in the industrial democracies. Economic Policy 13, 342-392.

Havrilesky, T., 1993. The Pressure on Monetary Policy. Kluwer Academic Publishers, Northwell, MA.

Kane, E., 1980. Politics and FED policy-making. Journal of Monetary Economics 6, 199-211.

Laffont, J.J., Tirole, J., 1993. A Theory of Incentives in Regulation and Procurement. MIT Press, Cambridge, MA.

O'Flaherty, B., 1990. The care and handling of monetary authority. Economics and Politics 2, $25-44$.

Peek, J., Rosemgren, E., Tootell, G., 1999. Is bank supervision central to central banking. Quarterly Journal of Economics 114, 629-653.

Persson, T., Tabellini, G., 1993. Designing institutions for monetary stability. Carnegie-Rochester Conferences Series on Public Policy 39, 58-94.

Posen, A., 1995. Declarations are not enough: Financial sector sources of central bank independence. In: Bernanke, B., Rotemberg, J. (Eds.), NBER Macroeconomic Annual. MIT Press, Cambridge, MA.

Rogoff, K., 1985. The optimal degree of commitment to an intermediate monetary target. Quarterly Journal of Economics 100, 1169-1189.

Rogoff, K., 1989. Reputation, coordination and monetary policy. In: R. Barro (Ed.), Modern Business Theory. Basil Blackwell, Oxford, pp. 236-264.

Svensson, L., 1995. Optimal inflation targets, conservative central banks and linear inflation contracts. CEPR Working Paper No. 1249, CEPR, London.

Tirole, J., 1986. Hierarchies and bureaucracies: On the role of collusion in organizations. Journal of Law, Economic and Organization 2, 181-214.

Tirole, J., 1992. Collusion and the theory of organizations. In: Laffont, J.J. (Ed.), Advances in Economic Theory, Vol. 2. Cambridge University Press, Cambridge, pp. 151-206.

Toma, M., 1982. Inflationary bias of the federal reserve system. Journal of Monetary Economics 10, $163-190$.

Waller, C., 1989. Monetary policy games and central bank politics. Journal of Money, Credit, and Banking $21,422-431$.

Waller, C., 1992. A bargaining model of partisan appointments to the central bank. Journal of Monetary Economics 29, 411-428. 
Waller, C., Walsh, C., 1996. Central bank independence, economic behavior, and optimal term length. American Economic Review 86, 1139-1153.

Walsh, C., 1995. Optimal contracts for independent central bankers. American Economic Review 85, 150-167.

Walsh, C., 1998. Monetary Theory and Policy. MIT Press, Cambridge, MA.

Wooley, J., 1984. Monetary Politics: The Federal Reserve and the Politics of Monetary Policy. Cambridge University Press, Cambridge. 